\title{
Comparative study of Pap smear test and VIA test in cervical carcinoma screening among women aged over 20 years
}

\author{
Alphonse Niyodusenga ${ }^{*}$, Emile Musoni1 ${ }^{1}$, Sarah Niyonsaba ${ }^{2}$ \\ ${ }^{1}$ University of Rwanda, College of Medicine and Health Sciences, School of Medicine and Pharmacy, \\ Department of Clinical Biology, Huye, Rwanda \\ ${ }^{2}$ Institute of Applied Sciences, INES-Ruhengeri, Faculty of Fundamental Applied Sciences, Department of \\ Biotechnology, Musanze, Rwanda
}

*Corresponding author: Alphonse Niyodusenga, University of Rwanda, College of Medicine and Health Sciences, School of Medicine and Pharmacy, Department of Clinical Biology, Huye, Rwanda, E-mail: niyodalph@yahoo.fr, Phone: (+250)788581592

\section{ABSTRACT}

\section{Objective}

To compare the performance of VIA and Pap smear tests as screening tools in cervical carcinoma detection in women.

\section{Methods}

The prospective and retrospective study was conducted on 198 women. Cervical smears were collected with Ayres's spatula. Acetic acid was used and the results were categorized as VIA positive and VIA negative. The Pap smear was reported according to the Bethesda system 2001. Cervical biopsy was done for all the cases.

\section{Results}

VIA was positive in $47.47 \%$ of the cases and Pap smear was positive in $39.89 \%$ of the cases. Among 198 cases, $61(30,8 \%)$ cases had cervical carcinoma. When we compared VIA and Pap smear tests, 94 cases were positive to VIA, and 61cases were confirmed positive with Pap smear. The sensitivity and specificity for VIA were $88.5 \%$ and $84.68 \%$, respectively. The sensitivity and specificity for Pap smear were $80.45 \%$ and $91.89 \%$, respectively. The sensitivity of VIA was higher than that of Pap smear. However, the specificity of VIA was low as compared to Pap smear.

\section{Conclusion}

VIA is a cost effective test and could be alternatively used with Pap smear in screening of cervical carcinoma but the Papanicolaou test is the most effective test for early detection of cervical carcinoma.

Keywords: Pap smear test; VIA test; cervical carcinoma; women

\section{INTRODUCTION}

Cervical carcinoma is uncontrolled growth that starts in the uterine cervical epithelium cells caused by several factors include Human Papilloma Virus (HPV).[1] The normal cells of the cervix gradually develop pre-cancerous changes that turn into cancer. There are 2 main types of cervical carcinoma: squamous cell carcinoma and adenocarcinoma. The squamous cells cover the surface of the exocervix. The second type of cervical carcinoma is adenocarcinoma which develops from mucus-producing glands cells of endocervix.[1]

Cervical cancer rates have fallen in most of the developed countries, probably as a result of screening and treatment programs. In contrast, the rates in most developing countries have risen or remained unchanged. In 2008 there were 529,000 new cases of cervical carcinoma, 
and more than 270,000 women die every year; $85 \%$ of them were from developing countries, especially in Africa where an estimated 53,000 women die of the cervical cancer every year. [2] Overall, $77 \%$ of new cases of cervical carcinoma and $88 \%$ of deaths occur in the developing world, where $95 \%$ of women have never been screened for this cancer.[3]

In sub-Saharan Africa, 34.8 new cases of cervical carcinoma are diagnosed per 100, 000 women annually, and 22.5 per 100,000 women die from the cervical carcinoma. These statistics were compared with 6.6 and 2.5 per 100,000 women, respectively, in North America. The drastic differences can be explained by lack of access to effective screening and services that facilitate early detection and treatment.[2]

Cervical carcinoma ranks as the second most frequent cancer among women in Rwanda. In 2008, Rwanda had 34.5 cases of cervical carcinoma and 25.4 deaths attributable to cervical cancer per 100,000 women.[4] Cervical carcinoma is rare in women under 30 years old and it is most common in women over 40 years, with the greatest number of deaths usually occurring in women aged between 50 and 60 years. Rwanda has a population of 3.90 million women over 15 years who are at risk of developing cervical carcinoma. Current estimates indicate that every year, 1304 women are diagnosed with cervical carcinoma and 921 die from the cervical cancer.[5] However, in Eastern Africa, about $33.6 \%$ of women in the general population are estimated to harbor cervical HPV infection at a given time,[6] and the HPV 16 or 18 types contribution to invasive cervical carcinoma ranged to $56.4 \%$ in 1994 and $91.5 \%$ in 2003.[7,8]

Cytology-based screening, however, has not proven to be as successful in low-resource settings of the developing world. Lack of trained pathologists and technicians and a deficiency of laboratories have contributed to that failure. Furthermore, Pap smears can miss cervical carcinoma, especially in low-quality laboratories; consequently they must be repeated every year to increase the chance of early detection.[9]

Epidemiological studies have consistently shown that the most important determinants of HPV infection in women are: the number of sexual partners, the age of initiation of sexual activity, and the sexual behavior of the male partner. Cervical carcinoma is preventable and curable if detected at early stage; but, in order to minimize cervical screening barriers in lowresource settings, strategies should be socially and culturally appropriate and health workers should be knowledgeable about correct procedures.[10] Although, the education about screening plays a vital role in cervical carcinoma prevention, most of Rwandese women are not aware about the symptoms and mode of transmission of cervical carcinoma.[3]

Papanicolaou (PAP) smear is a simple, safe, non-invasive and effective method for detection of pre-cancerous, cancerous and noncancerous changes in the cervix and vagina. The use of acetic acid during visual examination of the cervix, termed visual inspection with acetic acid (VIA), has been advocated as an alternative screening method to PAP smears in developing countries.[11] In this regards, the aim of this study was to compare VIA test and Pap smear test in order of assess their role in cervical carcinoma screening.

\section{METHODS}

This study was prospective and retrospective, comparative study carried out at Butare University Teaching Hospital (BUTH/CHUB), in Rwanda, southern province, District of Huye, in the departments of Gynecology and Anatomical Pathology from April 2011 to August 2014. Women aged 20 years and above who attended the gynecology department at CHUB with complaints of vaginal discharge, pelvic pain, post-coital bleeding were enrolled in this study. Women who had undergone hysterectomy or treatment for cervical pre-cancer or cancer, women with visible growth of cancer on the cervix, who are in menstrual period and pregnant women were excluded from the study. A total number of 198 women diagnosed or screened for cervical cancer at CHUB were included in this study. In this study, prospective and retrospective methods have been used. In prospective method, 20 samples were collected. In retrospective method, 178 samples were collected using both files in Gynecology and Anatomical Pathology department. 


\section{Sample collection}

During the data collection, the information on names, age, sex, the residential area, marital status and phone numbers, clinical pathological features of cervical carcinoma pelvic pain, vaginal bleeding, vagina discharge and grade of the tumor were obtained through a pre-designed structured data collection form.

The cervix was painted with $3-4 \%$ acetic acid and observed for aceto-white lesions (positive VIA) in gynecology department. Both negative and positive VIA results were collected by Ayres's spatula for Pap smear test. Samples were fixed in $95 \%$ ethyl alcohol and taken to the Pathology Department for interpretation. The Pap smear was reported according to the Bethesda system 2001. Patients with positive Pap smear results were again called back for biopsy. Biopsy served as the reference standard for cervical carcinoma diagnosis. Samples were analyzed using all steps of cytology and histopathology techniques. Cytology technique was Papanicolaou staining and histopathology technique was tissue processing. Samples were interpreted by a pathologist on light microscope (x400 magnification).

\section{Data analysis}

Data were registered on a paper data sheet and later analyzed using Microsoft Excel. Categorical variables were presented as frequency (n), percentage $(\%)$ in tables.

\section{Ethical considerations}

An authorization letter was given by INES administration. This study was carried out at CHUB after approval by the ethical committee of CHUB. The names of the patients were not recorded for ethical reason. All personal information was kept confidentially and only used for the study purposes.

\section{RESULTS}

In this study, the performance of VIA and Pap smear tests were analyzed and compared for a total of 198 women. The main symptoms as reason of testing were: the vaginal bleeding with $94(47.47 \%)$ cases followed by pelvic pain with $65(32.82 \%)$ cases and vaginal discharge with $39(19.69 \%)$ cases.

Table 1. The distribution of patients screened for cervical carcinoma according to age.

\begin{tabular}{|c|c|c|}
\hline \multicolumn{1}{|c|}{ Age range } & $\begin{array}{c}\text { Number of } \\
\text { participants }\end{array}$ & Percentage \\
\hline $21-30$ years & 17 & 8.6 \\
\hline $31-40$ years & 49 & 24.8 \\
\hline $41-50$ years & 64 & 32.3 \\
\hline $51-60$ years & 45 & 22.7 \\
\hline $61-70$ years & 23 & 11.6 \\
\hline \multicolumn{1}{|c|}{ Total } & 198 & 100 \\
\hline
\end{tabular}

In table 1 , the age range $31-40$ years and age range $41-50$ years show a high number of women screened for cervical carcinoma. 
Table 2. Distribution of VIA results according to age

\begin{tabular}{|c|c|c|c|c|c|}
\hline $\begin{array}{l}\text { Age } \\
\text { group }\end{array}$ & $\begin{array}{l}\text { Number of } \\
\text { participants }\end{array}$ & $\begin{array}{l}\text { Number of } \\
\text { acetowhite } \\
\text { positive }\end{array}$ & $\begin{array}{l}\text { \% of } \\
\text { the } \\
\text { total } \\
\text { sample }\end{array}$ & $\begin{array}{l}\text { Number of } \\
\text { acetowhite } \\
\text { negative }\end{array}$ & $\begin{array}{l}\text { \% of } \\
\text { the } \\
\text { total } \\
\text { sample }\end{array}$ \\
\hline $21-30$ & 17 & 4 & 2.02 & 13 & 6.56 \\
\hline $31-40$ & 49 & 11 & 5.55 & 38 & 19.19 \\
\hline $41-50$ & 64 & 29 & 14.64 & 35 & 17.67 \\
\hline $51-60$ & 45 & 38 & 19.19 & 7 & 3.53 \\
\hline $61-70$ & 23 & 12 & 6.06 & 11 & 5.55 \\
\hline Total & 198 & 94 & 47.47 & 104 & 52.52 \\
\hline
\end{tabular}

In table 2 , VIA positive tests were $47.47 \%$ overall. In the age range $51-60,38(19.19 \%)$ acetowhite positives has been tested; VIA negative results were $52.52 \%$ overall.

Table 3. Distribution of positive Pap smear results according to age

\begin{tabular}{|c|c|c|c|c|c|c|c|c|}
\hline $\begin{array}{c}\text { Age } \\
\text { range } \\
\text { (years) }\end{array}$ & LSIL & $\begin{array}{c}\text { \% of } \\
\text { the } \\
\text { total } \\
\text { sample }\end{array}$ & HSIL & $\begin{array}{c}\text { \% of } \\
\text { the } \\
\text { total } \\
\text { sample }\end{array}$ & SCC & $\begin{array}{c}\text { \% of } \\
\text { the } \\
\text { total } \\
\text { sample }\end{array}$ & $\begin{array}{c}\text { Total } \\
\text { Pap test } \\
\text { positive }\end{array}$ & $\begin{array}{c}\% \text { of } \\
\text { the } \\
\text { total } \\
\text { sample }\end{array}$ \\
\hline $21-30$ & 2 & 1.01 & 0 & 0 & 0 & 0 & 2 & 1.01 \\
\hline $31-40$ & 5 & 2.52 & 1 & 0.5 & 4 & 2.02 & 10 & 5.05 \\
\hline $41-50$ & 3 & 1.51 & 1 & 0.5 & 7 & 3.53 & 11 & 5.55 \\
\hline $51-60$ & 6 & 3.03 & 2 & 1.01 & 30 & 15.15 & 38 & 19.19 \\
\hline $61-70$ & 4 & 2.02 & 2 & 1.01 & 12 & 6.06 & 18 & 9.09 \\
\hline Total & 20 & 10.09 & 6 & 3.03 & 53 & 26.76 & 79 & 39.89 \\
\hline
\end{tabular}

LSIL: Low Squamous Intraepithelial Lesions, HSIL: High Squamous Intraepithelial Lesions, SCC: Squamous Cell Carcinoma.

In table 3, Pap smear test was positive in 79 (39.89\%) cases. Whereas a high level $53(26.76 \%)$ of SCC were diagnosed. 
Table 4. Distribution of negative Pap smear results according to age

\begin{tabular}{|c|c|c|c|c|c|c|c|c|}
\hline $\begin{array}{c}\text { Age } \\
\text { range } \\
\text { (years) }\end{array}$ & Normal & $\begin{array}{c}\text { \% of } \\
\text { the } \\
\text { total } \\
\text { sample }\end{array}$ & ASCUS & $\begin{array}{c}\% \text { of } \\
\text { the } \\
\text { total } \\
\text { sample }\end{array}$ & $\begin{array}{c}\text { Benign } \\
\text { cellular } \\
\text { changes }\end{array}$ & $\begin{array}{c}\% \text { of } \\
\text { the } \\
\text { total } \\
\text { sample }\end{array}$ & $\begin{array}{c}\text { Total } \\
\text { Pap test } \\
\text { negative }\end{array}$ & $\begin{array}{c}\% \text { of } \\
\text { the } \\
\text { total } \\
\text { sample }\end{array}$ \\
\hline $21-30$ & 12 & 6.06 & 2 & 1.01 & 1 & 0.5 & 15 & 7.57 \\
\hline $31-40$ & 33 & 16.66 & 4 & 2.02 & 2 & 1.01 & 39 & 19.69 \\
\hline $41-50$ & 23 & 11.61 & 5 & 2.52 & 25 & 12.62 & 53 & 26.76 \\
\hline $51-60$ & 0 & 0 & 4 & 2.02 & 3 & 1.51 & 7 & 3.53 \\
\hline $61-70$ & 0 & 0 & 4 & 2.02 & 1 & 0.5 & 5 & 2.52 \\
\hline Total & 68 & 34.34 & 19 & 9.59 & 32 & 16.16 & 119 & 60.1 \\
\hline
\end{tabular}

Table 4 shows that 119 (60.1\%) of women have been diagnosed as negative with Pap smear tests, Atypical Squamous Cells of Undifferentiated Significance (ASCUS) were 19 (9.59\%) cases and $32(16.16 \%)$ cases were benign cellular changes.

Table 5. Comparison of Pap smear test and VIA test

\begin{tabular}{|l|l|l|l|}
\hline & Pap smear positive & Pap smear negative & Total \\
\hline VIA positive & 61 & 33 & 94 \\
\hline VIA negative & 18 & 86 & 104 \\
\hline Total & 79 & 119 & 198 \\
\hline
\end{tabular}

In table 5, among 94 cases that were positive to VIA, 61 were confirmed positive with Pap smear, 18 of those that were negative to VIA were confirmed positive to Pap smear.

Table 6. Results of biopsy tests for cervical carcinoma screening.

\begin{tabular}{|l|c|c|}
\hline Biopsy test result & Number of cases & \% of the total sample \\
\hline Chronic cervicitis & 111 & 56.06 \\
\hline Mild dysplasia & 20 & 10.1 \\
\hline Moderate dysplasia & 2 & 1.01 \\
\hline Severe dysplasia & 4 & 2.02 \\
\hline SCC & 53 & 26.76 \\
\hline Adenocarcinoma & 8 & 4.04 \\
\hline Total & 198 & 100 \\
\hline
\end{tabular}


Table 6 shows biopsy results as a confirmation test. Mild dysplasia, moderate dysplasia, severe dysplasia and SCC were considered as positive for neoplasia. Final diagnostic by histopathology was taken as gold standard.

Out of 198 cases, 111 (56.06\%) were diagnosed as chronic cervicitis, 20 (10.1\%) as mild dysplasia (CIN I), 2 $(1.01 \%)$ as moderate dysplasia (CIN II), $4(2.02 \%)$ as severe dysplasia, $53(26.76 \%)$ as squamous cells carcinoma and $8(4.04 \%)$ as adenocarcinoma. Hence, biopsy test showed $87(43.9 \%)$ positive cases.

Table 7. Comparison of VIA and Pap smear tests to biopsy examination

\begin{tabular}{|l|l|l|l|}
\hline Tests & Positive biopsy & Negative biopsy & Total \\
\hline Positive VIA & 77 & 17 & 94 \\
\hline Negative VIA & 10 & 94 & 104 \\
\hline Positive Pap smear & 70 & 9 & 79 \\
\hline Negative Pap smear & 17 & 102 & 119 \\
\hline
\end{tabular}

Table 7 compares VIA and Pap smear tests to biopsy test. It presents true positives and true negatives, false positives and false negatives. For VIA test, the true positives were 77 for the presence of cervical carcinoma; 10 cases were false negatives; true negatives were 94 cases and false positive were 17 cases. For Pap smear, 70 cases out of 198 cases were true positive for the presence of cervical carcinoma; 17 cases were false negatives; true negatives were 102 cases and false positive were 9 cases.

Table 8 presents sensitivity, specificity, positive predictive value, negative predictive value and diagnostic accuracy of VIA and Pap smear tests

Table 8. Parameters of VIA and Pap smear tests

\begin{tabular}{|c|c|c|}
\hline Parameters & VIA estimate & Pap smear estimate \\
\hline Sensitivity $=\mathrm{TP} / \mathrm{TP}+\mathrm{FN}$ & $77 / 87 \times 100=$ & $70 / 87 \times 100=80.45 \%$ \\
& $88.5 \%$ & \\
\hline Specificity $=\mathrm{TN} / \mathrm{TN}+\mathrm{FP}$ & $94 / 111 \times 100=$ & $102 / 111 \times 100=91.89 \%$ \\
& $84.68 \%$ & \\
\hline Positive predictive value $=\mathrm{TP} / \mathrm{TP}+\mathrm{FP}$ & $\begin{array}{c}77 / 94 \times 100= \\
81.91 \%\end{array}$ & $70 / 79 \times 100=88.6 \%$ \\
\hline Negative predictive value $=$ & $94 / 104 \times 100=$ & $102 / 119 \times 100=85.71 \%$ \\
TN/TN+FN & $90.38 \%$ & \\
\hline Diagnostic accuracy $=$ & & $70+102 / 198=86.86 \%$ \\
(TP+TN) $/(\mathrm{P}+\mathrm{N})$ & $77+94 / 198=$ & \\
& $86.36 \%$ & \\
& & \\
\hline
\end{tabular}

TP: True positive, FP: False positive, TN: True negative, FN: False negative

As shown in table 8 , the sensitivity of VIA was $88.5 \%$ and that of Pap smear $80.45 \%$. The specificity of VIA was $84.68 \%$ and that of Pap smear was $91.89 \%$. The positive predictive value of VIA was $81.91 \%$ whereas that of Pap smear was $88.6 \%$. The negative predictive value of VIA was $90.38 \%$ whereas that of Pap smear was $85.71 \%$. The diagnostic accuracy of VIA was $86.36 \%$ whereas that of Pap smear was $86.86 \%$. 


\section{DISCUSSION}

The present study was conducted to compare the role of Acetic acid and Pap smear test as cervical carcinoma screening tools for women who attended CHUB. The age range of women involved in this study was 20-70 years. This age range is similar to that used by Khan $\mathrm{S}$ et al in 2007, where in their study, this screening method was studied in the age range of 25 to 65 years and also the age range of our study is related to that used by the American Cancer Society in 2013, which recommended all women to begin cervical carcinoma screening at age 21 to 65 years old.[1, 12] The age group ranging 51-60 years old was at high risk of developing the cervical carcinoma because this age group is the menopause period.

In this study, vaginal bleeding was the most common presenting complaint for cervical carcinoma with $63 \%$ of the cases. The second common complaint was pelvic pain in $23 \%$ and the last was vaginal discharge with $14 \%$ in case of cervical carcinoma. These complaints for cervical carcinoma are found in similar studies. In the study at Mysore Medical College and Research Institute by Suman K, in 2012, vaginal discharge was reported as the most common presenting complaint $(77.14 \%)$ followed by pelvic pain (43\%).[13] Also similar complaints were found in Sudan, where Dhabhadel et al, in 2008, reported pelvic pain as the most common complaint (56.8\%) followed by vaginal discharge $(27.43 \%)$.[14]

In present study, $10.1 \%$ cases of LSIL, and $3.03 \%$ cases of HSIL were reported. In contrast, Lozowiski, et al., in 1982, found that LSIL were $28.3 \%$ of cases and HSIL $70 \%$ of cases. In our study SCC cases $(26.76 \%)$ are higher than SCC cases reported by Lozowiski et al. (1. 5\%).[15] This large difference may be due to individual variations in the interpretation of Squamous Intra-epithelial Lesions.

In the present study, the proportion of women who were screened positive with VIA was $47.47 \%$ and with Pap smear it was $39.89 \%$. Our findings were higher than those observed in other studies in India by Divya $\mathrm{H}$ et al., in 2011 , which showed $12 \%$ cases of VIA positive while positive Pap smear were $11.7 \%$ cases. Singh K et al., in 2010 showed $16.2 \%$ cases of positive VIA and $5.2 \%$ cases of positive Pap smear.[16, 17] The reason for higher positivity rates of VIA and Pap smear tests in the present study may be that the current study was conducted in a referral hospital. It was done on hospital based population in which high risk cases were screened.

In the present study, the sensitivity of VIA was higher $(88.5 \%)$ than that of Pap smear $(80.45 \%)$. This result is similar to that found in the study conducted by Vadehra $\mathrm{K}$, et al., in 2006 where sensitivity of VIA was higher $(96.4 \%)$ than that of Pap smear (71.4\%).[18]

In our study, the specificity of VIA was lower at $(84.68 \%)$ as compared to Pap smear $(91.89 \%)$. Our results relate to the findings reported by Garg P. in 2011, where the specificity of VIA was $82 \%$ and that of Pap smear was $91.1 \%$. [19]

In the present study, the positive predictive value of Pap smear was higher $(88.6 \%)$ than that of VIA $(81.91 \%)$. The present results are similar to that found in University of Zimbabwe/JHPIEGO cancer project (1999) where the positive predictive value of Pap smear was elevated $(40.7 \%)$ than that of VIA (22.7\%).[20]

The negative predictive value for VIA was high than that of Pap smear $90.38 \%$ and $85.71 \%$ respectively. Garg P, in 2011, has found the equivalent rate where negative predictive value for VIA was $99.7 \%$ whereas Pap smears was $98.7 \%$. [19]

In the current study, the diagnostic accuracy of VIA was (86.36\%) whereas that of Pap smear was $(86.86 \%)$. These results are similar to that found by Albert et al., in 2012, where the diagnostic accuracy of VIA was $98.6 \%$ whereas for Pap smears it was 99.4\%.[21]

The specificity of VIA for cervical carcinoma screening would guide to over-treatment of non-neoplastic lesions. VIA is of particular interest in CHUB because it only requires equipment locally obtainable, and can be competently performed by non-physicians with prior training. The Pap smear stills the best method for screening of cervical carcinoma because of its high specificity. In addition, the sensitivity of VIA is higher than that of Pap smear test. Thus, VIA and Pap smear test could be alternatively used in the screening of cervical carcinoma. Further study is needed to compare the new cervical cancer screening test 
called HPV-DNA test with the tests used in the present study.

\section{REFERENCES}

1. American Cancer Society. Cancer Facts and Figures. 2013. Corporate center. American center society inc. 250 Williams street, MW, Antlanta,GA 30303 -1002, pp 1, 23.

2. World Health Organization (2013).Cancer: Fact sheets No 297. Web site retrieved February 2011 on line at ; http://www.who.int/mediacentre/factshee ts/fs297/en/

3. Binagwaho A, Ngabo F, Wagner CM, Mugeni C, Gatera M, Cameron TN. Nsanzimana S. Integration of comprehensive women's health programmes into health systems: cervical cancer prevention, care and control in Rwanda. Bull world Health organ. 2013 Sep 1,1,91 (9) 697-703. Doi 102471/BLT12116087

4. Information Centre on HPV and Cancer, Rwanda. Human papilloma virus and related diseases report, version posted at www.hpv.centre.net on 17 June 2019.

5. International Agency for Research on Cancer. GLOBOCAN 2008 -fact sheet: Rwanda. Lyon: IARC; 2008. Available from: http://globocan.iarc.fr/, [accessed 13 June 2013].

6. Bruni L, Diaz M, Castellsangue $X$, Ferrer E, Bosch FX, de Sanjose S. Cervical human papillomavirus prevalence in 5 continents: metaanalysis of 1 million women with normal cytological findings. J. Infect Dis. 2010; 202: 1789 1799. [PubMed] [Google Scholar].

7. Kay P, Soeters R, Necin J, Denny L, Dehaeck CM, Williamson AL. High prevalence of HPV 16 in South African women with cancer of the cervix and cervical intraepithelial neoplasia. J. Med.Virol. 2003; 71: 265-273 [PubMed][Google Scholar]

8. Williamson AL, Brink N.S, Dehaeck CM, Ovens S, Soeters R, Rybicki EP. Typing of human papilloma viruses in cervical carcinoma biopsies from Cape Town. J. Med. Virol. 1994; 43:231 - 237. [PubMed][Google Scholar].

9. Gaffikin L, Wittet S, Sherris J Expanding paradigms for cervical cancer screening: The Impact of the Alliance for Cervical Cancer Prevention. Path. 2013; pp; 1-25.
10. Nene B, Jayant $K$, Arrossi S, Shastri S, Budukh A. Determination of women's participation in cervical cancer screening trial. Maharashtra, India. Bulletin of the World Health Organization, 2006; 85, 264-272.

11. Ranu RB, Chandi C, Paral RD., and Subhash CB. Rapid Economic, Acetic Acid, Papanicolaou Stain (REAP) is it suitable alternative to standard PAP stain?J Med Sci . 2008; (2):99 -103.

12. Khan S, Jha R, Pant PR. Accuracy of cytology, visual inspection with acetic acid or lugol's iodine in cervical cancer screening. $N J$ Obstetric Gynecology. 2007; 2(2): 48-53.

13. Suman K. Evaluation of Pap smear and Acetic acid test as cervical cancer screening tools with histopathological correlation. 2012; pp 59-79.

14. Dhabhadel P, Vaidya A, Choudhary $P$. Early detection of precursors of cervical cancer with cervical cytology and visual inspection of cervix with acetic acid. Nepal Med Assoc. 2008; 4(170):71-6.

15. Lozowski MS, Mishriki YE, Solitare G. The combined use of cytology and colposcopy in enhancing diagnostic accuracy of preclinical lesions ofuterine cervix. Actacytol;1982;26(3):285 -91.

16. Divya H, Harish S, Prasanna KS. Diagnostic Value of VIA Comparing with Conventional Pap Smear in the Detection of Colposcopic Biopsy. NJOG 2011; 6(1):7-12.

17. Singh KN, More S. Visual inspection of cervix with acetic acid (VIA) in early diagnosis of cervical intraepithelial neoplasia (CIN) and early cancer cervix. The journal of obstetrics and gynecology of India. 2010; Jan-Feb; 60 (1):55-60.

18. Vadehra K, Jha R. Visual inspection using acetic acid and pap smear as a method of cervical cancer screening. J. of Institute of Medicine. 2006; 28(1):36-40. 
Rwanda Journal of Medicine and Health Sciences Vol.3 No.1, March 2020 https://dx.doi.org/10.4314/rjmhs.v3i1.4

19. Garg P. Evaluation of visual inspection with acetic acid (VIA) and visual inspection with neoplasia in comparison with cytologic screening. Obstetics and Gynaecology 2011; 2(6): $1-10$.

20. University of Zimbabwe /JHPIEGO cervical cancer project. Visual inspection with acetic acid for cervical cancer screening: test qualities in a primary-care setting. Lancet, 1999; 553; 869-73.
21. Albert SO, Oguntayo OA, and Samaila MAO. Comparative study of visual inspection of the cervix using acetic acid (VIA) and Papanicolaou (Pap) smears for cervical cancer screening. Ecancermedicalscience.2012:6:262. Doi; 10.3332/ecancer2012.262 PMCID:PMC 3408898, PMID22855689. 